\title{
Golpe en Brasil. Genealogía de una farsa
}

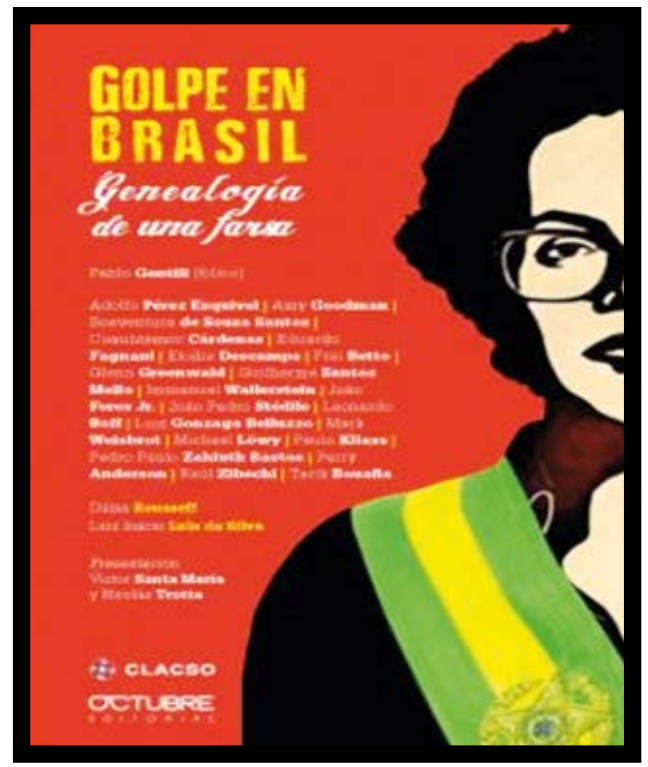

Golpe en Brasil: genealogía de una farsa / Perry Anderson [et al.] ; coordinación general de Pablo Gentili ; Víctor Santa María ; Nicolás Trotta. $1^{\underline{a}}$ ed. Ciudad Autónoma de Buenos Aires: CLACSO; Buenos Aires: Fundación Octubre; Buenos Aires: UMET, Universidad Metropolitana para la Educación y el Trabajo, 2016.

Golpe en Brasil reúne textos escritos entre abril y junio de 2016, período en el que se dio inicio al proceso de destitución de la presidenta Dilma Rousseff. Los autores aquí presentados nos ayudan a entender cómo se ha gestado y qué perspectivas se abren en el complejo proceso de desestabilización del orden democrático que vive actualmente Brasil. Escrito en la intensidad y la vertiginosidad de un proceso que aún está en curso, este libro pretende ser el testimonio de un momento trágico de la historia latinoamericana. La mayor nación de la región, la que supo liderar durante la última década un proceso de cambio y de transformaciones sociales sin precedentes; la que apoyó y promovió un activo proceso de integración regional, contribuyendo a su reconocimiento global como país soberano y solidario, dispuesto a revertir una historia de negación de derechos, de exclusiones y discriminación; Brasil, el país de todos, convertido ahora en el laboratorio de experimentación de un nuevo tipo de golpe institucional que puede extenderse por todo el continente. El golpe: la farsa. La aniquilación de la soberanía popular, base de la democracia, y su substitución por una república de autócratas corruptos. Brasil, el país donde la dictadura prometió durar un día y se instaló por larguísimos 21 años, nuevamente poniendo en evidencia el desprecio de sus élites hacia la democracia y hacia los derechos ciudadanos.

\section{Presentación}

Vivió nuestro subcontinente un inicio de milenio esperanzador. Emergieron nuevos liderazgos en la región más desigual del mundo. Hugo Chávez en Venezuela, Lula da Silva en Brasil, Néstor Kirchner en Argentina, Tabaré Vázquez en Uruguay, Evo Morales en Bolivia y Rafael Correa en Ecuador pincelaron un nuevo escenario, enterrando perspectivas concentradoras que reinaron durante siglos en nuestra América del Sur. Cuando parecía que 
el saqueo y la expoliación no tenían final, los pueblos nos dimos una nueva oportunidad.

Cada presidente inició, con sus matices, procesos de transformación que permitieron, en un contexto internacional favorable, iniciar un desarrollo con equidad en nuestras naciones. Comenzamos a recuperar el tiempo perdido, y el sueño de un proyecto de unión continental parecía posible. La obstrucción del ALCA, modelo de integración sesgada y desigual, en Mar del Plata en el 2005, desairando la presión de George W. Bush, constituyó una escena fundante que reafirmó una nueva perspectiva regional. Ese día América Latina ratificó su independencia. Por primera vez en la historia de nuestros países los gobiernos eran liderados por dirigentes populares que construyeron una empatía irrepetible.

Una década después mucho se avanzó, pero no lo suficiente. Cosechamos aciertos y errores en una agenda inconclusa. Nuevos integrantes se sumaron al sueño de una Sudamérica con justicia social.

Cristina Fernández de Kirchner en Argentina, Dilma Rousseff en Brasil y José Pepe Mujica en Uruguay, reafirmaron el acompañamiento popular de los gobiernos de sus antecesores. El destino nos arrancó prematuramente a Chávez y a Kirchner, pérdidas que hoy, más que nunca, impactan en el tablero político regional.

Todo proceso de reforma, que ataca a los intereses concentrados que se creen dueños del destino de nuestros países, implica resistencia.

La historia nos demuestra que hasta la justicia social tiene sus detractores. El golpe blando que sufrió Brasil es un ejemplo de ello. Las botas, los fusiles y los tanques, herramientas de los sectores oligárquicos durante el siglo $X X$, fueron reemplazados por la "dictadura" de los medios de comunicación y de importantes sectores del Poder Judicial. Han logrado sofisticar su esquema de usurpación del poder público, utilizando como ariete un vergonzante Congreso, que ni el liderazgo de Lula pudo transformar.
La estrategia desestabilizadora en Brasil se puso en marcha en el mismo instante que la alianza liderada por el Partido de los Trabajadores venció a Aécio Neves en 2014. Buscaron un atajo, sin escrúpulos, hasta que lo encontraron. La suspensión de Dilma Rousseff no respondió a ninguna de las investigaciones judiciales en curso, que tiene a muchos de sus responsables y cómplices en las bancas legislativas, sino a un infundado artilugio ilegal y anti democrático. Una Presidenta que no se encuentra imputada por delito alguno es suspendida por un Congreso que sintetiza lo peor de nuestras sociedades.

Todo se desmorona. La crisis venezolana, la derrota electoral del justicialismo en Argentina en manos de la derecha y la suspensión de Dilma, en un complejo contexto internacional, parece sentenciar el fin de un ciclo virtuoso de difícil repetición. Pero también pone a prueba la capacidad de recuperación de las fuerzas progresistas, nacionales y populares, y el forzado aprendizaje en base a los errores cometidos.

En su última visita a nuestra universidad, Pepe Mujica, recordando sus años de persecución, tortura y prisión, nos interpeló a ser conscientes de que sufrimos años más oscuros y pudimos superarlos. Ello sin dejar de reconocer los errores y la falta de coraje o decisión para enfrentar ciertos intereses. El retroceso político que transita nuestro subcontinente no se presenta sólo por la readecuación de la estrategia de los sectores conservadores, sino también por la incapacidad de las fuerzas progresistas en lograr profundizar las reformas y ampliar sus bases sociales.

No hay transformación social definitiva sin una alteración de los actores políticos tradicionales. Hoy el Partido de los Trabajadores, sus líderes Lula y Dilma, pero principalmente los sectores populares del Brasil, pagan el precio de no modificar la correlación de fuerzas y quedan rehenes de una política advenediza y especuladora. Similar escenario se impone sobre los sectores populares y trabajadores en la Argentina en estos escasos meses de gobierno neoliberal. 
Editar Golpe en Brasil: genealogía de una farsa es para nosotros una obligación. Callar frente al atropello que transita el Brasil, y sus sectores populares, es legitimar un quiebre institucional que pone en riesgo el futuro de Latinoamérica. El porvenir del Brasil, nuestro líder regional, es el de cada uno de nosotros. No hay espacio para la indiferencia.

El golpe institucional, a través de un juicio político express a Fernando Lugo en Paraguay en 2012, fue un ensayo preliminar, en una economía más pequeña, de esta estrategia de interrupción de los procesos populares. La visibilización del atropello es la más válida alternativa a la instrumentación de la farsa destituyente contra la Presidenta Rousseff y la generación de una conciencia colectiva que impida la instauración de un esquema de maquillado autoritarismo. En Brasil no sólo se encuentra en disputa la democracia. Está en juego un modelo social, un país para las élites, que excluye al pobre, al mulato, al negro, al "diferente" o un país que incluye, aquel que hoy se moviliza luchando por lo que le pertenece.

Nuestra Universidad, surgida de una organización de trabajadores, y hoy cogestionada por un colectivo de más de 45 sindicatos es única en el mundo y sintetiza el proceso de cambio que transitó la Argentina en la última década. Como universidad de los trabajadores y como herramienta de los sectores populares, tiene el deber de dar batalla en el campo de las ideas, en defensa de los intereses y de la dignidad de las mujeres y hombres que construyen todos los días, con su esfuerzo, el futuro de nuestros países. Por ellos, por cada trabajador y trabajadora, debemos dejar testimonio de lo que acontece, para transformar el presente y construir un futuro donde la igualdad deje de ser una utopía.

Buenos Aires, 18 de junio de 2016 